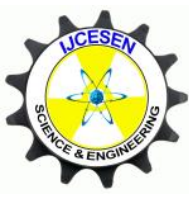

Copyright (C) IJCESEN
International Journal of Computational and

Experimental Science and $\boldsymbol{E N g i n e e r i n g}$

(IJCESEN)

Vol. 5-No.1 (2019) pp. 37-42

http://dergipark.gov.tr/ijcesen

Research Article

\title{
The Key Factor Analysis to the Reservoirs on the Basis of Bayesian Law
}

\author{
Jian SUN ${ }^{1 *}$, Qi LI ${ }^{1}$, Mingqiang CHEN $^{2}$, Zekai ZHANG ${ }^{3}$ \\ ${ }^{1}$ China University of Petroleum, College of Petroleum Engineering, 102249, Beijing -CHINA \\ ${ }^{2} \mathrm{Xi}$ 'an shiyou University, College of Petroleum Engineering, 710065, Xi'an -CHINA \\ ${ }^{3}$ Tarim Oil Field, 84100, Korla -China \\ * Corresponding Author : xjkelsj@163.com \\ ORCID: 0000-0002-5856-4824
}

\section{$\underline{\text { Article Info: }}$}

DOI: $10.22399 /$ ijcesen.422691

Received : 10 May 2018

Accepted : 21 February 2019

\section{Keywords}

Bayesian Law

Wushi Sag

Probability Theory

Poisson Distribution

Prospection

\begin{abstract}
:
The oil price shocks further exaggerates the inherent difficulties in studying exploration of complex reservoirs. Therefore, as the main way of reducing cost, it's necessary to analyze the main factors of complex reservoir formation before intensively exploration. Bayesian law is used to build a diagnostic model. Six key factors in the effectiveness of hydrocarbon reservoir are starting points. According to the maximum entropy principle and single well event's probability of drilled wells with prior probability, the probability of adverse factors in the forming of hydrocarbon reservoir can be concluded. Therefore, influencing degree of each factor can be obtained. Meanwhile, by the theory of Slicher, the distribution of oil and gas reservoirs conform to Poisson's distribution. The results can be applied to calculate the probability of hydrocarbon reservoir's discovery and to predict the exploration potential of survey region. From the perspective of testing, this paper use Wushi sag as an example. By using the single well event's probability of nine drilled wells and calculating the influence value of key factors which are adverse to form the hydrocarbon reservoir in Wushi sag, this paper focuses on the key aspects-poor reservoir condition and absent migration pathway. By applying Poisson's distribution to study the exploration prospect, this study reveals that there is at least one district where commercial gas reservoirs will be discovered in Wushi sag. In conclusion, the diagnostic model based on Bayesian law provides a new and unique way of thinking to solve the geological problems in complex condition, and it is effective to the petroleum geological knowledge.
\end{abstract}

\section{Introduction}

Along with the sustained decline in oil price and the fall in conventional crude oil, the complexities forming conditions of the reservoirs bring about serious problems like high cost and difficult exploration. In order to reduce the cost and workload of exploration, the reliable and meaningful method is to analyze major influential factors by corresponding mathematical method. Meanwhile, this method can forecast the oil exploration potential. The background of the proposed question is the exploration situation of Wushi sag. Up to now, the degree of exploration in this area is low. Before the 1990's, the main reconnaissance is geological survey. Later in the 1990's, the company Exxon obtained the mining rights and did some researches. However, Exxon claimed that it is too risky and costly for them to continue, so they finally gave up. Then the Tarim Oil Field Company did a lot of detailed prospecting about surface geology, seismic surveys and comprehensive researches and got some new ideas. One result of all these efforts is that well W1 was drilled and got commercial production [1]. However, the follow-on wells, such as Y2, Y101 and W2, were all dry holes. According to the above researching information of wells, another well S1 was drilled in 2005 and partly succeeded [2]. Since then nothing has been got from the wells such as S201, S3 and S4 [3]. The prospecting experience shows that the conditions in Wushi sag to form reservoirs are complex. The complex manifests in 
two ways. One is that multiphasic tectonic activities lead to intricate sedimentary facies. The other is that the key factors to reservoirs are uncertain. The poor quality of seismic data for the disadvantage surface creates an impediment to further perception. The only practicable way at present is to analyze the information from the drilled wells on the basis of Bayes formula. Then it is possible to make decision and guard exploration.

\section{Theory and methodology}

\subsection{The concept about mathematics}

Full probability formula: suppose that the sample space of stochastic experiment is $\mathrm{S}$. A is an event in experiment. $\mathrm{B} 1, \mathrm{~B} 2 \ldots \mathrm{Bn}$ is a partition in $\mathrm{S}$, and $\mathrm{P}$ (Bi) $>0(i=1,2 \ldots n)$ so

\section{$P(A)=P(B 1) P(A / B 1)+P(B 2) P(A / B 2)+$ ...P(Bi) $P(A / B i) \ldots . . .(1)$}

That means if it is impossible to get the probability of event A directly, it can be decomposed into a few reciprocal simple events. Then the probability of event A can be got by adding the probability of probabilities of simple events.

The most important thing is to find out a partition in sample space $S$, then event $A$ is divided into $n$ parts as $\mathrm{AB} 1, \quad \mathrm{AB} 2 \ldots \mathrm{ABn}$. That is, $\mathrm{A}=\mathrm{AB} 1+\mathrm{AB} 2+\ldots \mathrm{ABn}$. Therefore, by additive formula (1) can be attained.

Bayes formula:

$$
P\left(B_{i} \mid A\right)=\frac{P\left(B_{i}\right) P\left(A \mid B_{i}\right)}{\sum_{i=1}^{n} P\left(B_{i}\right) P\left(A \mid B_{i}\right)} \quad i=1,2 \ldots n \ldots \ldots .
$$

Assuming that the probability of event $\mathrm{A}$ is the sum of event groups $\mathrm{BiA}(\mathrm{i}=1,2 \ldots \mathrm{n})$ which are incompatible with each other on the basis of partition. Event $\mathrm{Bi}$ is the event leading to event $\mathrm{A}$. $\mathrm{P}$ (BiA) is the probability of leading result. If event happens, the probability of leading result by $\mathrm{Bi}$, $\mathrm{P}(\mathrm{BiA}) / \mathrm{P}(\mathrm{A})$ is a conditional probability. The Bayes formula can then be obtained by multiplication formula and total probability formula $[4,5]$.

\subsection{The introduction of geological concepts}

According to the theory on geology of petroleum, there are six key factors in the effectiveness of hydrocarbon reservoir: hydrocarbon source rocks in good conditions, reservoir bed in high quality, available cap rocks, good trap conditions, available migration conditions and steady preservation conditions. They are individually marked by letters $G, R, C, T, M, S$ in this paper and HR means hydrocarbon reservoir. In consideration of logic theory, we can express that six factors can be necessary and sufficient conditions to effectiveness of hydrocarbon reservoir. Thus we know that it's true for its converse-negative proposition. Then we can express its converse-negative proposition as the reasons which can be identified as poor hydrocarbon source rocks, reservoir bed in poor quality, unavailable cap rocks, poor trap conditions, unavailable migration conditions and unsteady preservation conditions for the ineffectiveness of hydrocarbon reservoir. The hydrocarbon reservoirs are destroyed, marked by capital letters $\bar{G}, \bar{R}, \bar{C}, \bar{T}, \bar{M}, \bar{S}$ and $\overline{H R}$. Only when the six key factors all in good conditions, it is possible to form an effective reservoir. By the identification of event, it can be described as:

$H R=G \cap R \cap C \cap T \cap M \cap S$

That is

$G \cap R \cap C \cap T \cap M \cap S \subset H R$

If one of these factors is in poor condition, it is impossible to form hydrocarbon reservoirs. With the identification of sum of events, it can be expressed as:

$H R \neq \overline{H R}=\bar{G} \cup \bar{R} \cup \bar{C} \cup \bar{T} \cup \bar{M} \cup \bar{S}$

That is

$\bar{G} \cup \bar{R} \cup \bar{C} \cup \bar{T} \cup \bar{M} \cup \bar{S} \subset \overline{H R} \neq H R$

With geologic theories and complete probability formula (1), if the probability of effective hydrocarbon reservoir is $\mathrm{P}(\mathrm{HR})$, sample space then can be partitioned into six events, which actually become a complete event group. Because the oil source $\operatorname{rock}(\mathrm{G})$, $\operatorname{reservoir}(\mathrm{R})$, $\operatorname{cap} \operatorname{rock}(\mathrm{C}), \operatorname{trap}(\mathrm{T})$, migration $(\mathrm{M})$, preservation $(\mathrm{S})$ are incompatible with each other, and $G \cup R \cup C \cup T \cup M \cup S=E$ constructs the effective condition to form effective hydrocarbon reservoir. So the requirements of formula of total probability and Bayesian law can be used to analyze geologic problems and predicate the oil and gas distribution. Therefore, it is necessary to get the prior probability, and it is crucial for the problem to be solved [5].

\section{Geological setting and geologic characteristics}

Wushi sag formed in late Himalaya Movement in Neogene is an intermontane depression located in the west of Kuqa foreland basin (Figure 1). It is limited by southern Tianshan tectonic belt in the north and fault in the south with Wensu uplift, spreading nearly from east to west as a long belt [6,7]. Wushi sag is a Neozoic deposit sag on 
Palaeozoic base, about 190 kilometers long from east to west and 35-40 kilometers wide from north to south with an area of about 3400 square kilometers. The tectonic setting is a combined action by tethyan tectonic belt from the end of Palaeozoic Era to Mesozoic Era (the southern Tianshan subduction orogeny belt) and Himalayan belt in Cenozoic Era (southern Tianshan collisional orogeny).

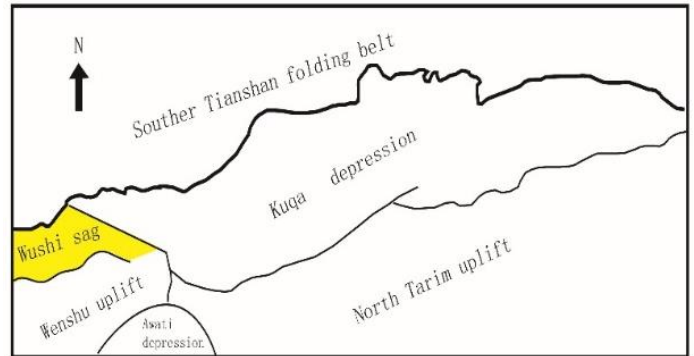

Figure 1. Schematic diagram showing the position of Wushi sag.

There are multiphasic tectonic activities in this area. The sag was initiated in Devonian-Permian. During Triassic-Jurassic, it is a downfaulted basin with steady sedimentary facies and the hydrocarbon source rocks in this area deposited [8]. In Cretaceous period, the depositional environments sustained and became the target stratum (Figure 2). From Early Tertiary to Miocene Epoch, extra-thick stratum was formed. Between Miocene Epoch and Quaternary, it was the time that the foreland basin formed with extensive sediment. At the end of Quaternary, a lot of thrust faults in huge scale and folds, influenced by the orogeny in later Himalayan movement, are formed. The main hydrocarbon source rocks being coal measure strata formed in lake facies in TriassicJurassic [9].

Generally, terrigenous sequence is controlled by tectonic movement. The strata in the southern Wushi sag is controlled by the fault between Wushi sag and Wensu uplift (Figure 2). The accommodation space in this area changes and develops along with faults activity, so various depositional system tracts are formed. (Unit I :Fault as boundary with steep slope, near provenance in deep water with alluvial fans; Unit II :Fault and steep slope as boundary with deep water having local secondary fault horst zonecomplex alluvial fans; Unit III :Double faults as boundaries, with shallow water-complex alluvial fans; Unit IV :Gentle slope, far away from provenance, shallow water with braided river deltas; Unit $V$ :Local secondary fault horst zone, far away from provenance with semi-deep water; Unit VI :Strike-slip fault, far away from provenance with semi-deep water; Unit VII :Gentle slope, far away from provenance, semi-deep water with deltas; Unit

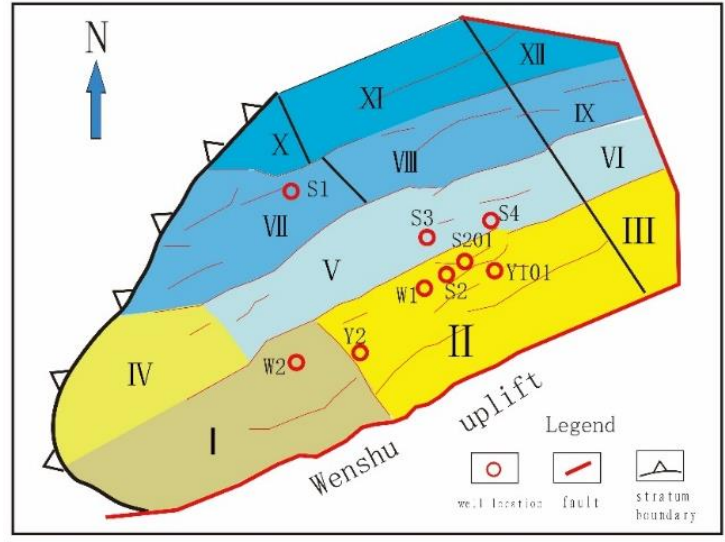

Figure 2. Schematic diagram of well locations-rift system-prospecting units.

VIII:Local secondary fault horst zone, far away from provenance with deep water; Unit IX: Strike-slip fault, local secondary fault horst zone, far away from provenance with deep water; Unit X:Gentle slope, far away from provenance with semi-deep water with subaqueous fans; Unit XI :Far away from provenance with deep water; UnitXII:Strike-slip fault as boundary with deep water-slope deep lake.)

In the early stage of lower sequence, due to the stronger fault activity, the accumulation space increases rapidly and topographic height difference is obvious. In W1 and Y101, coarse size sediments are found in low stand system tract (Figure 2), because they are close to Wensu uplift with rich provenance. S2 and S201 are far from the Wensu uplift, and fine size sediments are found (Figure 2). To the north, the water is deeper with hydrocarbon source rock. Lithologic traps and stratigraphic traps can be formed in the front of fan shaped lithosomic bodies, incised valleys and water transgression deltas and unconformity surface with underlying formation. With the development of fault, the setting velocity and the accumulation space increase to form the transgressive system-the sediments. To the north, the hydrocarbon source rocks distribute extensively because of the deeper water, but coarse size sediments deposit with smaller accumulation space and more obvious topographic height difference because of the faults activity in the sag, eg. S2 (Figure 2, 3A, 3B). There are transgressive actions of lithologic traps in the front of deltas and deep water turbidite fans. Then sediments deposit in the accumulation space to form the main target stratumhigh stand system, because the faults are less active in this area. The deepest water, deep lake mudstone and condensed section are critical in forming underlying ability of oil production. The deltas, fan deltas and turbidite fans in this stage are reservoirs with high quality to form lithologic traps. After Cretaceous, there are four sets of tectonic movements to form a set of traps and faults, which 
are late Yanshan Movement, early Himalaya movement, middle Himalaya movement and late Himalaya movement. The hydrocarbon rocks in the area of coal measure strata belonged to TriassicJurassic with extensive distribution. In this area, the Shushanhe formation in Cretaceous is the target zone [9]. According to the lithology, it can be divided into mud member, sand-conglomerate member and mudsand member from top to bottom, corresponding to two sequences [10]. Sequence 1: upper Yageliemu formation to middle sand-conglomerate member; sequence 2: middle sand-conglomerate member to mud member. There are three systems tracts in sequence1: upper Yageliemu formation-lower of lower mud member belongs to low stand system tract; lower to middle of lower mud member belongs to transgressive system tract; middle to upper of lower mud member to lower sand-conglomerate member belongs to high stand system tract. Sequence 2 can be divided into two system tracts: the low stand system tract correlating with member from the lower sand-conglomerate to the top of sandmud; transgressive system tract correlating with mud member (Figure 3A, 3B).

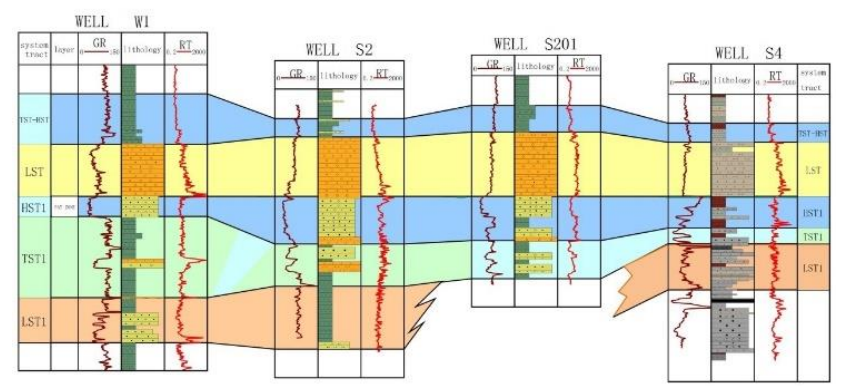

Figure 3A. Well Correlation in Wushi sag from east to west

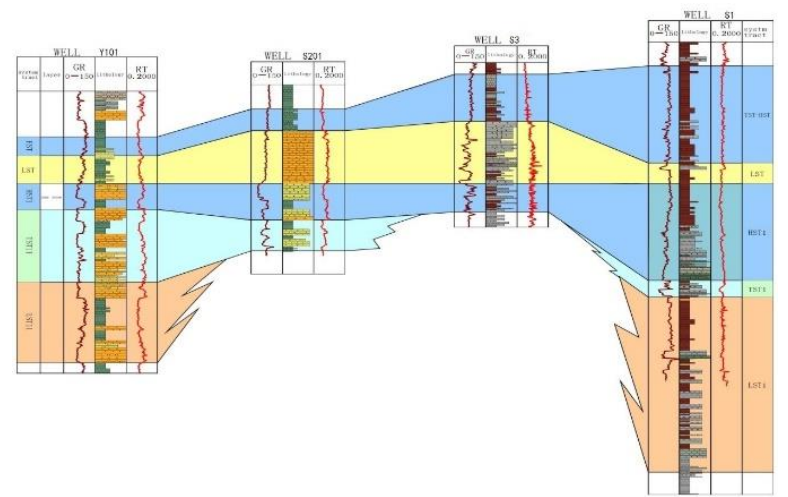

Figure 3B. Well Correlation in Wushi sag from north to South

The pay zone is the high stand system tract in sequence 1 with the facies of alluvial fans in the rocks of mud, silty shale, fine sandstone and conglomerate fine sandstone. Due to the great difference in sedimentary environment in this area, the thickness and components of target zone change both along the directions of trend (Figure 3A) and to the lake center (Figure 3B), leading the geologic condition too complex to identify.

\section{The application of Bayesian law in oil and gas predication \\ 4.1 The identification of prior probability}

The cap rock is the upper compaction conglomerate bearing calcium. With same tectonic background, the reservoirs have the same sealing condition. Because reservoirs, cap rocks, lithologic traps can be formed in plenty kinds of system tracts and the form, distribution and preservation of structural traps are controlled by tectonic movements, the weighting of oil source rock, reservoir, cap rock, trap, oil-gas migration and hydrocarbon preservation $(G, R, C, T, M, S)$ to form effective oil-gas traps is the same at one-sixth, so the prior probability of each factor is $P(G)=P(R)=P(C)=P(T)=P(M)=P(S)=1 / 6$.

By the way, theorectically the advisable prior probability can be attained by Bayes assumption with no known information. According to the Bayes assumption, when nothing is known about the prior probability, it is available to get the prior probability when it is considered as uniform distributed in the variable range. By the maximum entropy principle, for discrete information, it is supposed that the occurrence frequency of the sign for discrete information is $\mathrm{Pi}(\mathrm{i}=1,2 \cdots \mathrm{n})$. Then the information entropy can be identified as the expected information table from the sources of information.

$$
H(X)=-\sum P_{i} \log \left(p_{i}\right)
$$

It is entropy that characterizes the overall characteristics of uncertain degree for information source. Although it is less certain to get the information, the information quantity is abundant, as long as the information is available. For separate random variable, the entropy is at its maximum in equal probability mode [11].

Supposing Bayes on uniform distribution is accepted for prior probability, the result should be $P(G)=P(R)=P(C)=P(T)=P(M)=P(S)=1 / 6$. And the oil source rock, reservoir, cap rock, trap, oil-gas migration and hydrocarbon preservation $(G, R, C, T$, $M, S$ ) as discrete information sources, have the same information variant value by the maximum entropy principle. That is, $P(G)=P(R)=P(C)=P(T)=P(M)=P(S)=1 / 6$. By the analysis on actual facts and theory, the prior probability of each key factor to the effective reservoirs is one-sixth.

\subsection{The analysis of key factors for reservoir in Wushi sag}

The reasons for each failure well in this area can be got by geologic analysis (Table1). " $\sqrt{ }$ " and " $\mathrm{x}$ " 
stand for the favorable factors for the form of reservoirs $(A \subset H R$ ) and unfavorable factors for the form of reservoirs $(\bar{A} \subset \overline{H R})$.

Table 1. The factors to control the reservoirs from well

\begin{tabular}{|c|c|c|c|c|c|c|c|c|c|}
\hline \multicolumn{10}{|c|}{ in Wushi sag } \\
\hline $\begin{array}{c}\text { Well } \\
\text { factor }\end{array}$ & S1 & S2 & S201 & S3 & S4 & W1 & W2 & Y2 & Y101 \\
\hline $\begin{array}{l}\text { Source } \\
\text { rock } \\
\text { condition }\end{array}$ & $\sqrt{ }$ & $\sqrt{ }$ & $\sqrt{1}$ & $\sqrt{1}$ & $\sqrt{ }$ & $\sqrt{ }$ & $\sqrt{1}$ & $\sqrt{ }$ & $\sqrt{1}$ \\
\hline $\begin{array}{l}\text { Reservoir } \\
\text { condition }\end{array}$ & $\sqrt{ }$ & $\sqrt{ }$ & $\sqrt{ }$ & $\mathrm{x}$ & $\mathrm{x}$ & $\sqrt{ }$ & $\mathrm{x}$ & $\mathrm{x}$ & $\mathrm{x}$ \\
\hline $\begin{array}{l}\text { Cap rock } \\
\text { condition }\end{array}$ & $\sqrt{ }$ & $\sqrt{ }$ & $\sqrt{1}$ & $\sqrt{1}$ & $\sqrt{ }$ & $\sqrt{ }$ & $\sqrt{1}$ & $\sqrt{ }$ & $\sqrt{1}$ \\
\hline $\begin{array}{l}\text { Trap } \\
\text { condition }\end{array}$ & $\sqrt{ }$ & $\sqrt{ }$ & $\mathrm{x}$ & $\sqrt{1}$ & $\sqrt{ }$ & $\sqrt{ }$ & $\mathrm{x}$ & $\mathrm{x}$ & $\sqrt{ }$ \\
\hline $\begin{array}{l}\text { Migration } \\
\text { condition }\end{array}$ & $\checkmark$ & $\sqrt{ }$ & $\sqrt{2}$ & $\mathrm{x}$ & $\mathrm{x}$ & $\sqrt{2}$ & $\mathrm{x}$ & $\mathrm{x}$ & $\mathrm{x}$ \\
\hline $\begin{array}{l}\text { Sealing } \\
\text { condition }\end{array}$ & $\sqrt{ }$ & $\sqrt{ }$ & $\sqrt{ }$ & $\sqrt{ }$ & $\sqrt{ }$ & $\sqrt{ }$ & $\sqrt{ }$ & $\sqrt{ }$ & $\sqrt{1}$ \\
\hline
\end{tabular}

By analyzing the data in Table 1, the information of each key factor can be figured out (Table 2). Using Bayes formula, the $\mathrm{P}(\mathrm{A} \mid \mathrm{Bi})$ of adverse factors in the forming of hydrocarbon reservoir can be concluded (Table 2). Ordering the values in sequence from the largest to the smallest, the key factors destroying the hydrocarbon reservoir can be shown.

Table 2. The cartogram of failure factors in wells, Wushi sag

\begin{tabular}{|l|l|l|l|l|l|l|}
\hline $\begin{array}{l}\text { failure } \\
\text { factor }\end{array}$ & $\bar{G}$ & $\bar{R}$ & $\bar{C}$ & $\bar{T}$ & $\bar{M}$ & $\bar{S}$ \\
\hline number & $\mathbf{0}$ & $\mathbf{5}$ & $\mathbf{0}$ & $\mathbf{3}$ & $\mathbf{5}$ & $\mathbf{0}$ \\
\hline $\mathbf{P}(\mathbf{A} \mid \mathbf{B i})$ & $\mathbf{0}$ & $\mathbf{0 . 5 5 5 6}$ & $\mathbf{0}$ & $\mathbf{0 . 3 3 3 3}$ & $\mathbf{0 . 5 5 5 6}$ & $\mathbf{0}$ \\
\hline
\end{tabular}

Table 2 is the probability of failure wells from Bayes formula corresponding to various factors. For example, failure probability because of the poor reservoir $\bar{R}$ is:

$P(\bar{R} \mid \overline{H R})=$

$P(\bar{R}) P(\overline{H R} \mid \bar{R})$

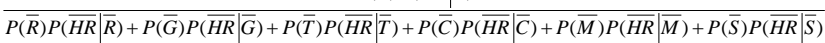

By plugging data into the formula, the result can be obtained as the following:

$$
P(\bar{R} \mid \overline{H R})=\frac{\frac{1}{6} \times \frac{5}{9}}{\frac{1}{6} \times \frac{5}{9}+\frac{1}{6} \times \frac{0}{9}+\frac{1}{6} \times \frac{3}{9}+\frac{1}{6} \times \frac{0}{9}+\frac{1}{6} \times \frac{5}{9}+\frac{1}{6} \times \frac{0}{9}}=0.3846
$$

Table 3. The failure probability of factors, Wushi sag

\begin{tabular}{|l|l|l|l|l|l|l|}
\hline failure factor & $\bar{G}$ & $\bar{R}$ & $\bar{C}$ & $\bar{T}$ & $\bar{M}$ & $\bar{S}$ \\
\hline$P\left(\overline{B_{i}} \mid \overline{H R}\right)$ & $\mathbf{0}$ & $\mathbf{0 . 3 8 4 6}$ & $\mathbf{0}$ & $\mathbf{0 . 2 3 0 8}$ & $\mathbf{0 . 3 8 4 6}$ & $\mathbf{0}$ \\
\hline
\end{tabular}

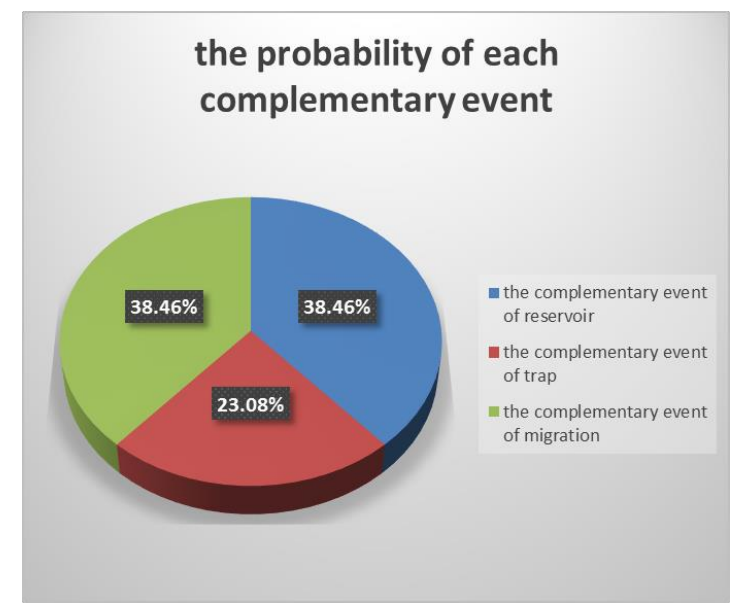

Figure 4. The probability of each complementary event

By the way, the failure probability of each key factor can be figured out (Table 3). So in conclusion, from Table 3 and Figure 4, there are three key factors leading to the spoiled oil-gas reservoir, which are poor reservoir condition, poor trap condition and the absent migration pathway. If the corresponding factor is sorted by value, it can be mathematically expressed as $\bar{R}=\bar{M}>\bar{T}$.

Thus, for the oil and gas exploration in Wushi sag, more attention should be paid to the range of reservoir distribution, reservoir lithology, reservoir quality and the faults connecting the underlying hydrocarbon rocks, unconformity characters and the relationship among the reservoir, faults and unconformities. Then the trap quality is the following aspect which is worthy of attention. Therefore, all these factors are directly related to problem that whether or not more oil and gas reservoirs with commercial production will be explored.

\subsection{The number of potential hydrocarbon reservoirs}

The Wushi sag can be divided into twelve districts sorted by standards such as the distance from the provenance, the boundary style, the slope ratio (gentle or steep), and the depth of water (Figure 2). The oil and gas reservoir is one of the mineral resources in nature. By the theory of Slichter, the distribution of oil and gas reservoirs conforms to Poisson's distribution. Currently, the reservoirs conditions, in Wushi sag, are that one district with one gas reservoir (unitVII), one district with two gas reservoirs (unit II ) and ten without reservoirs (Table

4). The $\lambda$ can be attained by unbiased estimation:

$$
\lambda=\frac{\sum_{k=0}^{2} k \times f_{k}}{\sum_{k=0}^{2} f_{k}}=\frac{0 \times 10+1 \times 1+2 \times 1}{10+1+1}=\frac{3}{12}=0.25
$$

Then $\lambda$ is plugged into Poisson equation (5) 


$$
P\{X=k\}=\frac{\lambda^{k} e^{-\lambda}}{k !} \ldots \ldots
$$

Table 4. The number of oil and gas reservoirs discovered in units

\begin{tabular}{|l|c|c|c|c|c|c|c|c|c|c|c|c|}
\hline Unit & I & II & III & IV & V & VI & VII & VII & IX & X & XI & XII \\
\hline $\begin{array}{l}\text { Oil and gas } \\
\text { reservoirs } \\
\text { discovered }\end{array}$ & 0 & 2 & 0 & 0 & 0 & 0 & 1 & 0 & 0 & 0 & 0 & 0 \\
\hline
\end{tabular}

The probability of potential oil and gas reservoirs in Wushi sag can be figured out (Table 5). The percentage of districts without oil and gas reservoirs is $77.88 \%$. In fact, up to now, the percentage of districts in which no oil and gas reservoirs have been found is $83.33 \%$. The percentage of districts where the gas reservoirs have been found is $5.45 \%$ $(83.33 \%-77.88 \%=5.45 \%)$. The number of districts where oil and gas reservoirs will be found is $12 * 0.0545=0.654 \approx 1$. That is, in Wushi sag, there is at least one district where commercial oil and gas reservoirs can be discovered.

Table 5. The number of oil and gas reservoirs predicted by Poisson equation

\begin{tabular}{|c|c|c|c|c|}
\hline $\begin{array}{c}\text { The number of } \\
\text { gas reservoirs } \\
\text { discovered(K) }\end{array}$ & $\begin{array}{c}\text { Frequent } \\
\text { number(fx) }\end{array}$ & frequency & $K^{*} \mathbf{f} \mathbf{x}$ & $\begin{array}{c}\text { Poisson } \\
\text { theoretical } \\
\text { probability }\end{array}$ \\
\hline 0 & 10 & 0.830 & 0 & 0.7788 \\
\hline 1 & 1 & 0.083 & 1 & 0.1947 \\
\hline 2 & 1 & 0.083 & 2 & 0.0243 \\
\hline$\Sigma$ & 12 & $0.996 \approx 1$ & 3 & $0.9978 \approx 1$ \\
\hline
\end{tabular}

\section{Conclusions}

The probability theory is a rigorous and logical subject. In principle, the regularities among objectivities will be understood and mastered. On the basis of Bayes formula and information from well, the key factors to control the reservoirs can be identified.

The key factors in Wushi sag are reservoir condition and migration pathway. So, in the following stage, the researches about sequence stratigraphy, sedimentary and structures should be emphasized. Also the relationship between sectonic process with high quality reservoirs and the form of migration pathway deserves more attention.

In conclusion, by applying Bayes formula into available well information, the hydrocarbon potential is predicted. What's more, combining Bayes formula with the knowledge of oil geology provides an effective way to solve puzzling problems which can not be solved by other geological ways.

\section{Acknowledgment}

Grateful acknowledgement is made to my teacher, Professor Chen Mingqiang, who gave me considerable help by means of suggestion, comments and criticism. In addition, I deeply appreciate the contribution to this thesis made by my friend, Zhang Bo.

\section{References}

[1] Gong Deyu, Li Ming et al. (2014) Geochemical Characteristics and Origins of the Oils in Wushi Sag, Tarim Basin. Natural Gas Geoscience Vol.25 No.1 Jan.

[2] Lei Ganglin, Ran Qigui et al. (2013) Characteristics and Controlling Factors of Mesozoic Reservoirs in Eastern Wushi Sag, Tarim Basin. XINJIANG PETROLEUM GEOLOGY. Vol.34 No.1Feb. 17-19.

[3] Zhou Yanzhao, Lu Xuesong et al. (2016) The main controlling factors of reservoir physical property and oiliness in the structural lithologic reservoirs in the east of Wushi Sag, Kuqa foreland basin. Natural Gas Geoscience. Vol.27 No.6 Jun.

[4] Advanced Mathematics Teaching Research Group of Zhejiang University. (1985) Engineering MathematicsProbability Theory and Mathematical Statistics. Beijing: Higher Education Press, 21-26.

[5] Wang Rongxin (1996) Mathematical Statistics. Xian: Xi'an Jiaotong University Press.

[6] Zhang Zhenhong, Lv Xiuxiang et al. (2004) Petrogeologic feature of Wushi Sag in Talimu Basin. Journal of $\mathrm{Xi}^{\prime}$ an Shiyou University(Natural Science Edition) Vol.18 No. 4Jul. 29-31+65-3.

[7] Jia Jinhua, Zhou Dongyan et al. (2004) Petroleum geologic characteristics of Wushi Sag in Tarim Basin. ACTA PETROLEI SINICA. Vol.25 No.6Nov. 12-17.

[8] Zheng Min, Peng Gengxin et al. (2008) Structural pattern and its control on hydrocarbon accumulations in Wushi Sag, Kuche Depression, Tarim Basin. PETROLEUM EXPLORATION AND DEVELOPMENT. Vol.35 No.4Aug. 444451.

[9] Zhang Bo, Li Jianghai et al. (2007) PRELIMINARY DISCUSSION ON GEOLOGICAL DISTRIBUTION OF METAMORPHICCORE COMPLEX AND HYDROCARBON IN KUCHE DEPRESSION. NATURAL GAS GEOSCIENCE. Vol.18 No.2Apr. 200-203.

[10] Yang Fan, Jia Jinhua (2006) Alluvial Fan and Fandelta Sedimentary Facies and Favorable Assemblage of Reservoir and Seal of Wushi Sag (Cretaceous) in Tarmi Basin. ACTA SEDIMENTOLOGICA SINICA Vol.24 No.5Oct. 681-689.

[11] Yu Hai, Chen Yong et al. (2008) The Way to Identify the Prior probability Distribution on the Base of Maximum Entropy Principle Risk. CHINA SCIENCE AND TECHNOLOGY INFORMATION. Feb. 276-277. 